\title{
Musical Therapy with Balinese Flute Increased Cognitive Function, Brain-derived Neurotrophic Factor Serum Levels, and Decreased Interleukin-6 Serum Levels among the Elderly in West Denpasar Primary Health Clinic
}

\author{
I. Made Oka Adnyana*, Ni Putu Ayu Putri Mahadewi, A.A.A. Putri Laksmidewi \\ Department of Neurology, Division of Headache, Faculty of Medicine, Udayana University, Sanglah Hospital, Denpasar, Bali, \\ Indonesia
}

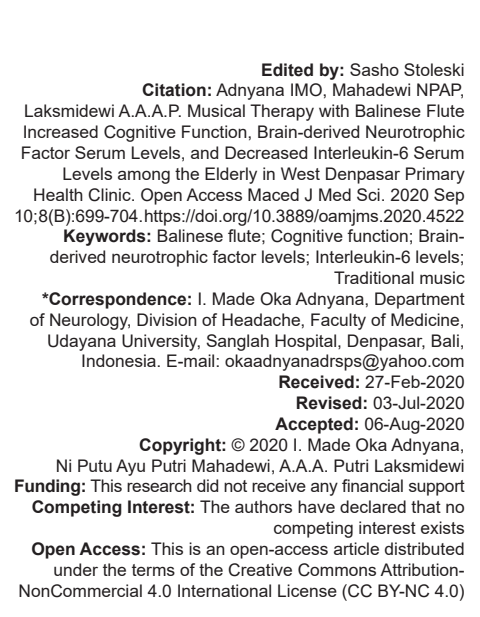

\section{Introduction}

Music is an entertaining and amusing instrument, often used to improve patient's general health condition. Musical therapy has been widely used to treat mental disorders as well as somatic diseases. Musical therapy exerts positive impacts toward health, including relieving stress, relaxation, pain management, improvement of cardiovascular system, and cognitive function, both on the clinical and outpatient settings [1], [2].

Studies have shown the effects of music toward biological function of human beings as proven by multiple parameters, including heart rate and blood pressure. Interestingly, improved cognitive function was probably due to stress-relieving effect of musical therapy and its impact toward multiverse of emotional manifestations. These changes were caused by changes in molecular production and signaling through increased messenger secretion, including hormones, neurotransmitters, and growth factor proteins [3].

According to the Indonesian Health Law no. 131998 related to the well-being of the elderly, someone can be categorized as the elderly if he or she has reached more than or equal to 60 years of age. As life expectancy in Indonesia increases, there will be increased population number of elderly as well. Center of Data and Information Ministry of Health Republic of Indonesia stated that human life expectancy in Indonesia increased from 68.6 years in 2001-2015 to 70.8 years old. In 2030-2035, life expectancy is projected to increase to become 72.2 years old. Aging process was characterized by decline in cognitive function, including memory, decision-making capacity, and delayed in motor system.

Music is an instrument with therapeutical effect to improve cognitive function. Among them, classical music is a composition originating from European culture 
and categorized by certain periodicity. By listening to classical music, one can derive positive effect so-called "Mozart effect" or "Vivaldi effect." Listening to Western classical music has been proven to improve cognitive function, particularly the memory and visuospatial domains [4].

Music also induces changes in endocrine system by which it affects the clinical manifestation of biological systems. For instance, changes in steroidal hormone and its receptor will influence brain neuroplasticity. This includes brain-derived neurotrophic factor (BDNF) as one of the growth factors which has a role in brain neuroplasticity. Neuroplasticity is related to cellular response and determine neuron's ability to adapt to various needs. Impairment of this mechanism may yield psychopathological disturbance [5]. In addition, music also influences immune system. Recreational music is able to modulate immune response among subjects age 65 years old, marked by changes in production of lymphocytes, T cells, CD4+T cells, memory $T$ cells, interferon gamma, and interleukin (IL)-6 [6], [7]. There is a Balinese musician named Agus Teja Santosa, S. Sn, whose famous for his musical artwork of playing flute made of tiing buluh (a certain type of Balinese bamboo). He has created a musical instrument composition entitled "Morning Happiness," which is very gentle and slow, thus frequently played in several public facilities in Bali [8].

The impact of musical therapy against cognitive function has never been studied before in Denpasar, Bali. According to this fact, supported by the widely known positive impact of musical therapy toward improvement of cognitive function, we would like to address the question if an addition of traditional Balinese flute musical composition entitled "Morning Happiness" in Western classical music improved cognitive function as well as BDNF and IL-6 levels among the elderly in Denpasar Primary Health Clinic 1 and 2 in West Denpasar, Bali.

\section{Methods}

As many as, 40 elderly who fulfilled inclusion criteria participated in this study. Those people were divided into two groups, that is, treatment and control groups, each with 20 participants. Participants were asked to listen to music from a recorder with earphone on both ears prepared by the investigator. Recorder device being used was mobile enjoy mp3 player sized $5 \times 3 \mathrm{~cm}$ which has a clip behind it. Meanwhile, the control group was given Western classical composition frequently used for cognitive research, like "Spring" by Antonio Lucio Vivaldi. Participants from the control group were administered Vivaldi's composition of "Spring" for 20 min for 21 days from Primary Health
Clinic 1 in West Denpasar. On the other hand, treatment group was given Vivaldi's composition like those received by control group, plus an additional composition of "Morning Happiness" by Mr. Agus Teja Sentosa, S. Sn for 20 min everyday in the morning for a total of consecutive 21 days in Primary Health Clinic 2 in West Denpasar, Bali.

Among two groups, cognitive evaluation was performed using Montreal Cognitive Assessment (MoCA)-INA and blood sample was withdrawn during the $1^{\text {st }}$ day for BDNF and IL-6 levels measurement. Investigators ensure that study participants listened to the composition routinely by calling the close relatives and/or the study participants him/herself through phone to listen to the music in time. On day 22, MoCA-INA was reassessed and blood sample was withdrawn again to measure BDNF and IL-6 levels. This study was conducted after received ethical clearance from Ethical Committee from the Department of Research and Development Faculty of Medicine, Udayana University/ Sanglah Hospital, Denpasar.

BDNF and IL-6 levels were measured using ELISA procedure according to manuals from R\&D system 614 MCKinley Place, NE, Minneapolis, MN 55413 USA as follows:

\section{Preparation steps}

1. Buffer solution. If concentrate forms crystal, solution should be heated in room temperature, stir until crystal dissolves. Dilute with $20 \mathrm{~mL}$ of wash buffer concentrate to into deionized water, thus formed $500 \mathrm{~mL}$ of buffer solution.

2. Substrate solution. Reagents $A$ and $B$ of equal volume were mixed for $15 \mathrm{~min}$, covered from direct light.

3. Human free BDNF standard. Human free BDNF was reordered using Calibrator Diluent RD6P for serum sample. This reorder process yielded a solution of $4000 \mathrm{pg} / \mathrm{mL}$. This solution was waited for a minimum of $15 \mathrm{~min}$.

4. Usage of polypropylene. A $300 \mu \mathrm{L}$ of solution was dropped to each tube and mixed before used.

\section{Test procedure}

Put all the reagents and samples on room temperature before being used. It is recommended that all standards, samples, and controls were duplicated.

1. Prepare all standard reagents and samples according to the previous procedures.

2. Discard excess microplates from the plate frame, then return to the foil bag containing preservative and resealed.

3. Add $100 \mu \mathrm{L}$ of assay diluent RD1S into each container. 
4. Add $50 \mu \mathrm{L}$ of standard control and sample into each container. Close with the prepared container. Incubate for $2 \mathrm{~h}$ under room temperature.

5. Add $100 \mu \mathrm{L}$ of human free BDNF conjugate into each container. Close with the new sealant and incubate for $1 \mathrm{~h}$ under room temperature.

6. Aspirate every container and wash, repeat the process twice with thrice rinsing process. Wash with buffer solution (400 $\mu \mathrm{L})$ added into each container. After last rinsing, discard all remaining buffer solution with aspiration. Turn upside down plate and blot facing towards the clean towel underneath it.

7. Add $200 \mu \mathrm{L}$ of substrate solution into each container. Incubate for $30 \mathrm{~min}$ under room temperature, cover from light.

8. Add $50 \mu \mathrm{L}$ of stop solution into each container. The color of the solution will turn from blue to yellow. If the color is green or there is inhomogenous color, tap the plate slowly.

9. Ensure optical density of each container during $30 \mathrm{~min}$ was $450 \mathrm{~nm}$ using reading set microplate. If long wave correction is available, reset to $540-570 \mathrm{~nm}$. If long correction is not available, reduce reading to a wavelength of $540 \mathrm{~nm}$ or $570 \mathrm{~nm}$ from the reading with 450 $\mathrm{nm}$ wavelength. This subtraction will correct the optical imperfection in the plate. Direct reading from $450 \mathrm{~nm}$ without correction may yield higher and less accurate results.

\section{Statistical analyses}

All statistical analyses were conducted using IBM SPSS Statistics 20. Normality test was conducted using Shapiro-Wilk and data were normally distributed. Data regarding baseline characteristics were performed using independent t-test, whereas difference of mean MoCA-INA was evaluated with Wilcoxon signed-rank test and independent t-test and subcategory of MoCAINA test was evaluated using Mann-Whitney U-test. Differences of BDNF before and after treatment were evaluated using paired t-test, difference of BDNF between case and control with independent t-test, and difference of IL-6 before and after treatment were tested using Wilcoxon signed-rank test, and IL-6 decrement was evaluated with Mann-Whitney U-test with $p<0.05$ which was deemed statistically significant.

\section{Results}

According to Table 1, data were normally distributed and there was no significant difference between the control and treatment groups in all baseline
Table 1: Baseline characteristics of research participants

\begin{tabular}{llll}
\hline Variables & \multicolumn{2}{l}{ Group } & p value \\
\cline { 2 - 2 } & Control $(\mathrm{n}=20)$ & \multicolumn{1}{l}{ Treatment $(\mathrm{n}=20)$} & \\
\cline { 1 - 2 } $\begin{array}{l}\text { Age average (years) } \\
\text { Sex }(\%)\end{array}$ & $65.70 \pm 4.23$ & $69.35 \pm 4.32$ & 0.948 \\
$\quad$ & & & \\
$\quad$ Male & $10(50)$ & $10(50)$ & 1.000 \\
$\quad$ Female & $10(50)$ & $10(50)$ & \\
$\begin{array}{l}\text { Recent education levels }(\%) \\
\quad \text { Junior high school }\end{array}$ & $12(60)$ & $9(45)$ & 0.86 \\
$\quad$ Senior high school & $2(10)$ & $4(20)$ & \\
$\quad$ Academy/diploma/university & $6(30)$ & $7(35)$ & \\
Occupations (\%) & & & \\
$\quad$ Retired civil servants & $8(40)$ & $9(45)$ & \\
$\quad$ Private employee & $6(30)$ & $6(30)$ & \\
$\quad$ Entrepreneurs & $4(20)$ & $1(5)$ & \\
$\quad$ Others & $2(10)$ & $4(20)$ & \\
Mean initial MoCA-INA score & $20.75 \pm 3.39$ & $21.50 \pm 3.02$ & 0.968 \\
Mean initial BDNF levels & $25125.45 \pm 7436,60$ & $26507.40 \pm 5666.17$ & 0.132 \\
Mean initial IL-6 levels & $3.15 \pm 2.25$ & $3.76 \pm 3.09$ & 0.279 \\
\hline MoCA: Montreal Cognitive Assessment, BDNF: Brain-derived neurotrophic factor, IL: Interleukin. &
\end{tabular}

characteristics, comprising age, sex, education level, occupation, initial MoCA-INA score, BDNF, and IL-6 levels $(p>0.05)$.

On Table 2, there was a significant difference between initial and endpoint MoCA-INA test results among the treatment and control groups $(p<0.001)$, but there was no significant difference between the control and treatment $(p=1.00)$. On the other hand, BDNF levels differed significantly between initial and endpoint BDNF levels among the control group ( $p$ $<0.001$ ), but did not differ significantly between the control and treatment groups $(p=0.534)$. Meanwhile, there was no significant difference between initial and endpoint IL-6 levels between the control groups, but there was a close to statistical difference between of initial and endpoint IL- 6 levels among the treatment group $(p=0.052)$. However, there was no significant difference between the control and treatment groups for this parameter $(p=0.133)$. According to profile analysis of MoCA-INA score based on cognitive domain, there was a significant difference in the memory domain between the control and treatment groups $(p=0.01)$, whereas other domains did not (Table 2).

\section{Discussion}

Daily activities and cognitive stimuli have role in inducing brain plasticity. Listening to music or listening to music while dancing influences brain plasticity. In addition, musical instruments such as piano, harp, violin, guitar, and flute exert therapeutic effects to those who listen to it [9], [10].

Music exerts positive effect toward working memory and perception processing speed and motor ability. Those who like to play piano will have superior motor ability when compared with those who do not. Music is a form of cognitive exercise which exerts neuroprotective effects. In fact, music has been used to improve cognitive function among dementia and multiple approaches with sounds have been studied. The elderly 
Table 2: Increment and mean change differences profile of MoCA-INA (including each cognitive domain), BDNF, and IL-6 levels $\left({ }^{*} \mathrm{p}<0.05\right)$

\begin{tabular}{|c|c|c|c|c|c|c|c|}
\hline Parameters & Group & Initial mean & Endpoint mean & Mean difference & $\mathrm{p}$-value & $95 \% \mathrm{Cl}$ & p-value of two groups \\
\hline \multirow[t]{2}{*}{ MoCA-INA } & Control & $20.75 \pm 3.39$ & $24.95 \pm 3.43$ & $4.20 \pm 1.77$ & $<0.001$ & $-2.19-0.19$ & 1.000 \\
\hline & Treatment & $21.50 \pm 3.02$ & $26.70 \pm 2.68$ & $5.20 \pm 1.94$ & $<0.001$ & & \\
\hline \multirow[t]{2}{*}{ BDNF } & Control & $22318.67 \pm 9436.37$ & $24586.67 \pm 9898.50$ & $2268.0 \pm 487.65$ & $<0.001$ & $-2345.99-584.45$ & 0.198 \\
\hline & Treatment & $24335.0 \pm 2382.80$ & $27483.67 \pm 2561.76$ & $3148.67 \pm 990$ & $<0.001$ & & \\
\hline IL-6 & Treatment & $3.76 \pm 3.09$ & $2.23 \pm 1.23$ & $1.52 \pm 2.90$ & 0.052 & & \\
\hline \multicolumn{8}{|c|}{ MoCA-INA increment score profile according to cognitive domain } \\
\hline \multicolumn{2}{|l|}{ Variables } & \multicolumn{2}{|l|}{ Control } & \multicolumn{2}{|l|}{ Treatment } & \multicolumn{2}{|l|}{$p$-value } \\
\hline \multicolumn{2}{|c|}{ Visuospatial/executive } & \multicolumn{2}{|l|}{$0.95 \pm 0.61$} & \multicolumn{2}{|l|}{$1.15 \pm 1.04$} & \multicolumn{2}{|l|}{0.1} \\
\hline \multicolumn{2}{|l|}{ Naming } & \multicolumn{2}{|l|}{$0.15 \pm 0.67$} & \multicolumn{2}{|l|}{0} & \multicolumn{2}{|l|}{0.32} \\
\hline \multicolumn{2}{|l|}{ Attention } & \multirow{2}{*}{\multicolumn{2}{|c|}{$1.2 \pm 1.15$}} & \multicolumn{2}{|l|}{$1.95 \pm 1.32$} & \multicolumn{2}{|l|}{0.72} \\
\hline \multicolumn{2}{|l|}{ Language } & & $0.40 \pm 0.60$ & \multicolumn{2}{|l|}{$0.35 \pm 0.59$} & \multicolumn{2}{|l|}{0.74} \\
\hline \multicolumn{2}{|l|}{ Abstraction } & \multicolumn{2}{|l|}{$0.35 \pm 0.50$} & \multicolumn{2}{|l|}{$0.25 \pm 0.45$} & \multicolumn{2}{|l|}{0.19} \\
\hline
\end{tabular}

who often plays musical instrument or listening to music less often suffers from dementia [11], [12].

As many as, 40 study participants whom each group consists of 20 subjects were involved. Average age of the treatment and control groups was $65.70 \pm 4.23$ and $69.35 \pm 4.32$ years old, respectively $(p>0.05)$, whereas there was no significant difference for education and occupation between the control and treatment groups $(p>0.05)$.

MoCA-INA test results increased on both control and treatment groups, that is, $4.20 \pm 1.77$ (95\% confidence interval confidence interval [Cl] 2.9-0.9; $p<0.001)$ and $5.20 \pm 1.94(95 \% \mathrm{Cl}-2.9-0.9$; $\mathrm{p}<0.001$ ), respectively. According to neuropsychiatric mechanisms, musical therapy using "Spring" from four seasons album of Vivaldi reduced anxiety which also reflects toward memory improvement [13]. Similar findings were also obtained by Foster and Valentine who concluded that listening to Western classical music for $10 \mathrm{~min}$ was able to increase cognitive function [4]. The study by Sung et al. has shown that listening to music for 2-3 times/week for 1-6 weeks was able to improve cognitive function [14].

In addition, cognitive improvement between the control and treatment groups did not differ significantly $(p=1.000)$. This finding was probably due to different response between individuals toward music, that is, influenced by history, location, culture, and taste of their listeners [15]. All participants in this study were of Balinese and they are used to listening to Balinese traditional music which always has flute component in other, thus additional flute sounds might not affect the results significantly.

Memory domain differed markedly between the control and treatment groups $(p<0.01)$. This result was in accordance with those obtained by Palisson et al. who obtained that musical therapy improved episodic memory function among Alzheimer patients [16]. Meanwhile, Dege and Kerkovius observed significant impacts of musical therapy toward verbal and visual memory [17]. The study by Mammarela et al. found that memory function improved among the elderly who listens to classical music, although not all domains experienced improvement [18].
BDNF levels among the control group increased significantly post-intervention (28264.75 \pm 9102.02), and this differed significantly with pre-intervention levels $(25125.45 \pm 7436.6$; p $<0.01$ ). On the other hand, intervention group did not experience significant changes of BDNF levels, before and after intervention $(p=0.526)$. The study by Marzban et al. found that BDNF levels increased significantly among postnatal rats induced with Mozart Sonata KV 448 musical composition $(p<0.001)$ [19]. This finding was in accordance with other studies which applied basic physical fitness activity among elderly women who also experienced increased cognitive function and BDNF levels among the treatment group, before and after exercise $(p=0.011)$. This was due to the well-studied effect of Western classical music in increasing BDNF levels. BDNF is a neurotrophic factor which has a role in neuroplasticity, neuronal differentiation, and neurogenesis. In hypothalamus, BDNF, and its receptor, tropomyosin-related kinase B has a role in metabolism. In hippocampus, it affects neuronal plasticity and neurogenesis which is important for learning process and memory function [20]. We found that BDNF levels among the treatment and control groups, before and after intervention did not differ significantly ( $p=0.526$ and 0.534 , respectively). This was probably due to Balinese people are used to listening to traditional classical music beforehand, during daily activity and flute was frequently used on traditional Balinese dancing, such as gambuh, jogged, gong kebyar, and semar pegulingan [21]. Therefore, Balinese flute did not affect neuroplasticity to a significant extent among both groups, as reflected by the corresponding BDNF levels. In addition, the intensity of listening to flute music between treatment and control was difficult to be precisely quantified. Moreover, BNDF levels were highly influenced by confounding factor including alcohol consumption, smoking, and physical activity [22], [23], [24].

Musical effect toward release of biochemical response has been studied and this was thought due to physiological response. Musical therapy also exerted positive effects toward emotion, stress relieve, and immune function [3]. The impact of music on immune status on patients undergoing surgery has been studied, 
like those done by Conrad et al. who obtained that declining hydroepiandrosterone, epinephrine, and IL-6 levels were observed by the administration of musical therapy [25]. The study by Fancourt et al. who studied the effect of drum music among depressed and anxious patients, along with inflammatory response found that antiinflammatory cytokine like IL-4 decreased significantly with $10 \%$ reduction of pro-inflammatory cytokine including MCP on week 6 post-treatment $(p<0.05)$ [26]. In addition, IL-17 levels also decreased to an almost significant level $(p=$ 0.099). However, TNF- $\alpha$ and IL-6 did not differ significantly ( $p=0.875, p=0.454$, respectively). This study revealed that there was a decline of IL-6 almost to a significant extent among the treatment group ( $p=0.052)$. This was due to influence of music to growth hormone accompanied by decrease of IL-6 among patients treated with Mozart music [25]. Listening to Mozart music was able to increase activity in several brain regions and involved the process of listening indirectly. Musical effect toward the release of growth hormone from pituitary gland was a central effect causing sedation. This effect was an indirect consequence against sympathetic nerve through non-specific changes of the immune response. The release of growth hormone was stimulated by growth hormone releasing factor (GHRF) from the hypothalamus. Growth hormone synthesized by the hypothalamus was also found in immune system. In fact, the study had shown the inverse correlation between GHRF levels and IL-6 released from the peripheral mononuclear blood cells [27].

There were several weaknesses in this study, that is, we did not evaluate factors responsible for changes of BDNF levels, including mood, immune status, smoking, and daily physical activities, such as aerobic or other routine sports.

We suggest that the influence of flute music against mental status (mood and stress) in the elderly should be conducted separately, thus able to be compared with already well-documented and studied music therapy (Mozart).

\section{Conclusion}

Balinese traditional flute composition was proven to be non-inferior when compared with Western classical composition as it improved mainly memory domain accompanied by increasing BDNF and decreasing IL-6 levels.

\section{References}

1. Salimpoor VN, Benovoy M, Larcher K, Dagher A, Zatorre RJ. Anatomically distinct dopamine release during anticipation and experience of peak emotion to music. Nat Neurosci. 2011;14(2):257-62. https://doi.org/10.1038/nn.2726

PMid:21217764

2. Yamasaki A, Booker A, Kapur V, Tilt A, Niess H, Lillemoe KD, et al. The impact of music on metabolism. Nutrition. 2012;28(1112):1075-80. https://doi.org/10.1016/j.nut.2012.01.020 PMid:22858194

3. Gangrade A. The effect of music on the production of neurotransmitters, hormones, cytokines, and peptides: A review. Music Med. 2012;4(1):40-3. https://doi. org/10.1177/1943862111415117

4. Foster NA, Valentine ER. The effect of auditory stimulation on autobiographical recall in dementia. Exp Aging Res. 2001;27(3):215-28. https://doi. org/10.1080/036107301300208664

PMid:11441644

5. Calabrese F, Rossetti AC, Racagni G, Gass P, Riva MA, Molteni R. Brain-derived neurotrophic factor: A bridge between inflammation and neuroplasticity. Front Cell Neurosci. 2014;8:430. https://doi.org/10.3389/fncel.2014.00430 PMid:25565964

6. Fukui $\mathrm{H}$, Yamashita M. The effects of music and visual stress on testosterone and cortisol in men and women. Neuro Endocrinol Lett. 2003;24(3-4):173-80.

7. Koyama M, Wachi M, Utsuyama M, Bittman B, Hirokawa K Kitagawa M. Recreational music-making modulates immunological responses and mood states in older adults. J Med Dent Sci. 2009;56(2):79-90.

PMid:20099470

8. Soni A. Harumkan Indonesia Dengan Music Tradisional Kompasiana; 2013.

9. Joseph A, Ulrich R. Sound Control for Improved Outcomes in Healthcare Settings, Report. The Center for Health Design; 2007.

10. Bherer L. Cognitive plasticity in older adults: Effects of cognitive training and physical exercise. Ann NY Acad Sci. 2015;1337:1-6. https://doi.org/10.1111/nyas. 12682 PMid:2577361

11. Wan CY, Schlaug G. Music making as a tool for promoting brain plasticity across the life span. Neuroscientist. 2010;16(5):566-77. https://doi.org/10.1177/1073858410377805 PMid:20889966

12. Baird A, Samson S. Music and dementia. Prog Brain Res. 2015;217:207-35. PMid:25725917

13. Irish M, Cunningham CJ, Walsh JB, Coakley D, Lawlor BA, Robertson $\mathrm{IH}$, et al. Investigating the enhancing effect of music on autobiographical memory in mild Alzheimer's disease. Dement Geriatr Cogn Disord. 2006;22(1):108-20. https://doi. org/10.1159/000093487

PMid:16717466

14. Sung HC, Chang AM, Lee WL. A preferred music listening intervention to reduce anxiety in older adults with dementia in nursing homes. J Clin Nurs. 2010;19(7-8):1056-64. https://doi. org/10.1111/j.1365-2702.2009.03016.x

PMid:20492050

15. Chanda ML, Levitin DJ. The neurochemistry of music. Trends Cogn Sci. 2013;17(4):179-93.

PMid:23541122

16. Palisson J, Roussel-Baclet C, Maillet D, Belin C, Ankri J, Narme P. Music enhances verbal episodic memory in Alzheimer's disease. J Clin Exp Neuropsychol. 2015;37(5):503-17. https:// doi.org/10.1080/13803395.2015.1026802

PMid:25951905 
17. Dege $F$, Kerkovius $K$. The effects of drumming on working memory in older adults. Ann N Y Acad Sci. 2018;4:13685. https://doi.org/10.1111/nyas.13685

PMid:29727035

18. Mammarella N, Fairfield B, Cornoldi C. Does music enhance cognitive performance in healthy older adults? The Vivaldi effect. Aging Clin Exp Res. 2007;19(5):394-9. https://doi.org/10.1007/ bf03324720

PMid:18007118

19. Marzban M, Shahbazi A, Tondar M, Soleimani M, Bakhshayesh M, Moshkforoush A, et al. Effect of mozart music on hippocampal content of BDNF in postnatal rats. Basic Clin Neurosci J. 2011;2(3):21-6.

20. Noble EE, Billington CJ, Kotz $\mathrm{CM}$, Wang C. The lighter side of BDNF. Am J Physiol Regul Integr Comp Physiol. 2011;300(5):R1053-69.

PMid:21346243

21. Chung JT. Kajian Akustik Suling Bali Dalam Gambelan Kebyar (Tesis), Program Pasca Sarjana Institut Seni Indonesia Bali. Bali: Institut Seni Indonesia Bali; 2015. https://doi.org/10.31091/ mudra.v34i3.794

22. Chan KL, Tong KY, Yip SP. Relationship of serum brain-derived neurotrophic factor (BDNF) and health-related lifestyle in healthy human subjects. Neurosci Lett. 2008;447(2-3):124-8. https://doi.org/10.1016/j.neulet.2008.10.013

PMid:18852019

23. Currie J, Ramsbottom R, Ludlow H, Nevill A, Gilder M.
Cardio-respiratory fitness, habitual physical activity and serum brain derived neurotrophic factor (BDNF) in men and women. Neurosci Lett. 2009;451(2):152-5. https://doi.org/10.1016/j. neulet.2008.12.043

PMid: 19133315

24. Bus BA, Molendijk ML, Penninx BJ, Buitelaar JK, Kenis G, Prickaerts $J$, etal. Determinantsofserumbrain-derivedneurotrophic factor. Psychoneuroendocrinology. 2011;36(2):228-39. https:// doi.org/10.1016/j.psyneuen.2010.07.013

PMid:20702043

25. Conrad C, Niess H, Jauch KW, Bruns CJ, Hartl W, Welker L. Overture for growth hormone: Requiem for interleukin-6? Crit Care Med. 2007;35(12):2709-13. https://doi.org/10.1097/01. ccm.0000291648.99043.b9 PMid:18074473

26. Fancourt D, Perkins R, Ascenso S, Carvalho LA, Steptoe A, Williamon A. Effects of group drumming interventions on anxiety, depression, social resilience and inflammatory immune response among mental health service users. PLoS One. 2016;11(3):e0151136. https://doi.org/10.1371/journal. pone. 0151136

PMid:26974430

27. Siejka A, Stepien T, Lawnicka H, Krupinski R, Komorowski J, Stepien $\mathrm{H}$. Effect of the growth hormone-releasing hormone [GHRH(1-44)NH2] on IL-6 and IL-8 secretion from human peripheral blood mononuclear cells in vitro. Endocr Regul. 2005;39(1):7-11. https://doi.org/10.1016/j.npep.2003.12.001

PMid:16107133 